\title{
Metsulfuron-methyl no desempenho agronômico e na qualidade das sementes de trigo
}

\section{Metsulfuron-methyl over agronomic performance and seed quality of wheat crop}

\author{
Alfredo Junior Paiola Albrecht ${ }^{1}$; Leandro Paiola Albrecht ${ }^{2}$; Rafaela Alenbrant Migliavacca ${ }^{3}$; \\ Deivid Lincon Reche ${ }^{1}$; Aline de Carvalho Gasparotto ${ }^{1}$; Marizangela Rizzatti Âvila ${ }^{4}$
}

\begin{abstract}
Resumo - Na cultura do trigo são escassos os resultados científicos referente ao uso de herbicidas, limitando as informações sobre os efeitos que estes causam. Neste contexto, o objetivo deste trabalho foi avaliar alguns componentes da produção e a qualidade das sementes do trigo sob o efeito da aplicação de doses crescentes de metsulfuron-methyl em dois estádios de desenvolvimento, tendo como pressuposto que o emprego de altas doses em combinação com o estádio de desenvolvimento possa afetar a planta. Com este intuito foi conduzido um ensaio a campo, em que os tratamentos foram compostos por cinco doses do herbicida metsulfuronmethyl: $0 ; 1,8 ; 3,6 ; 5,4 ; 7,2$ g i.a. ha ${ }^{-1}$; aplicadas em dois estádios da cultura: 4 e 10.4. As variáveis avaliadas foram: produtividade, massa de mil sementes, germinação e vigor. Com base nos resultados obtidos pode-se concluir que o herbicida metsulfuron-methyl pode ser nocivo à cultura do trigo, apenas quando se utiliza o incremento das doses na fase de espigamento.
\end{abstract}

Palavras-chave: Triticum aestivum, herbicida, rendimento, qualidade fisiológica.

\begin{abstract}
On wheat crop there is scarce scientific evidence regarding the use of herbicides, limiting the information about their effects. In this context, the objective of this work was to evaluate some yield components and seed quality of wheat crop under the effect of increasing doses application of metsulfuron- methyl in two stages of development, from the premise that the use of high doses in combination with developmental stage may affect the plant. With this purpose an experiment was conducted in field conditions, in which treatments consisted of five doses of metsulfuron-methyl herbicide: $0 ; 1.8 ; 3.6 ; 5.4 ; 7.2 \mathrm{~g}$ a.i. $\mathrm{ha}^{-1}$, applied at two crop stages: 4 and 10.4. Variables evaluated were: yield, thousand seed mass, germination and vigor. According to obtained results, it's possible to conclude that metsulfuron-methyl herbicide may be harmful to wheat crop, only when it is used doses increment at silking stage.
\end{abstract}

Key-words: Triticum aestivum, herbicide, yield, physiological quality.

\footnotetext{
${ }^{1}$ Acadêmico (a) de Graduação em Agronomia, Universidade Estadual de Maringá/UEM, Av. Colombo 5790 87020-900 Maringá, PR.

${ }^{2} *$ Eng. Agr., Dr., Professor do Depto de Ciências Agronômicas, Universidade Estadual de Maringá - CAU/UEM. Estrada da Paca s/ n - Bairro São Cristovão - 87507-190 Umuarama, PR. e-mail: lpalbrecht@yahoo.com.br

${ }^{3}$ Acadêmica de Graduação em Agronomia, Universidade Estadual de Maringá - CAU/UEM.

${ }^{4}$ Eng $^{\mathrm{a}}$. Agr., Dra., Pesquisadora do Instituto Agronômico do Paraná/IAPAR, Rod. PRT 163 km 188 - 85825 -000, Santa Tereza do Oeste, PR.
} 


\section{Introdução}

O trigo é um dos cereais mais produzidos no mundo. No Brasil, a produção anual oscila entre cinco e seis milhões de toneladas. O consumo anual no país tem se mantido em torno de 10 milhões de toneladas, havendo a necessidade de importação. O grão é consumido na forma de pão, massa alimentícia, bolo e biscoito, além disso, é usado também como ração animal, quando não atinge a qualidade exigida para consumo humano (COMISSÃO SUL-BRASILEIRA DE PESQUISA DE TRIGO, 2005).

Existem poucas alternativas de herbicidas seletivos recomendados para as culturas de inverno. Devido à falta de informações, alguns agricultores usam produtos de forma indevida e podem colocar em risco a saúde humana e o meio ambiente. Um dos fatores determinantes para se manter altas produtividades é o manejo adequado das plantas daninhas, pois estas interferem no crescimento e desenvolvimento das espécies cultivadas (Papa et al., 2005). Por exemplo, na cultura do trigo, a massa seca, a produtividade de grãos e a absorção de nitrogênio são reduzidos como o aumento da densidade de plantas daninhas (Iqbal \& Wright, 1999).

Metsulfuron-methyl é um dos herbicidas mais utilizados para o controle de plantas daninhas em pós-emergência na cultura do trigo (Vagas \& Roman, 2005). Este herbicida, pertencente ao grupo das sulfoniluréias, caracterizado por alta atividade biológica (eficaz em doses relativamente baixas) e seu grande espectro de ação.

Apresenta grande versatilidade e atualmente de custo baixo, o que faz com que, em muitos casos, seja utilizado de maneira indiscriminada pelos agricultores (Leaden, 2002), como observado em acompanhamentos de campo em regiões do estado do Paraná, por exemplo, à noroeste.
Atualmente, os baixos custos e o surgimento de plantas daninhas que apresentam considerável resistência a este produto fizeram com que os produtores aumentassem a frequencia de uso deste herbicida, podendo causar fitotoxicidade a cultura, o que pode afetar o bom desempenho da cultura e a utilidade de um sistema prático e econômico de manejo de plantas daninhas na safra de inverno.

As altas doses do produto, associadas ao uso de maneira indevida, assim como as condições ambientais desfavoráveis podem levar a sintomas de fitotoxicidade na cultura, afetando negativamente o crescimento das plantas e seu desempenho final (Salvagiotti et al., 2001).

Como as informações sobre os efeitos que este herbicida pode causar sobre os componentes de produção e a qualidade fisiológica das sementes de trigo são escassas, faz-se necessário pesquisas nesta área.

Neste contexto, o objetivo do presente trabalho foi avaliar o efeito da aplicação de doses crescentes de metsulfuron-methyl em dois estádios da cultura, sobre a produtividade, a massa de mil sementes, a germinação e o vigor das sementes de trigo, em duas safras, na região noroeste do estado do Paraná.

\section{Material e métodos}

O experimento foi instalado no Município de Marialva, localizada na região noroeste do estado do Paraná, situada a $51^{\circ} 47^{\prime} 30^{\prime \prime}$ de longitude oeste de Greenwich e $23^{\circ} 29^{\prime} 06^{\prime \prime}$ de latitude sul, com altitude média de 670 metros. O clima predominante na região é do tipo Cfa, mesotérmico úmido, com verões quentes, chuvas abundantes e invernos secos, segundo classificação de Köppen (IAPAR, 1987). 
O solo da área experimental é classificado como Latossolo Vermelho eutroférrico (EMBRAPA, 1999) de textura muito argilosa e relevo plano. O sistema de preparo do solo empregado foi o direto, sobre a palhada da cultura da soja. A adubação e os tratos culturais, incluindo manejo de pragas e doenças, foram os mesmos preconizados pelo sistema de produção para a região (COMISSÃO SUL-BRASILEIRA DE PESQUISA DE TRIGO, 2005).

As avaliações foram conduzidas no Laboratório de Tecnologia de Sementes da Universidade Estadual de Maringá (UEM), Campus Avançado de Umuarama - CAU/CCA, em Umuarama, PR.

A cultivar de trigo utilizada foi IPR 85, com hábito de crescimento intermediário e ciclo precoce, com maturação média aos 113 dias. As sementes de trigo da cultivar em questão, foram semeadas em duas safras 27/04/2008 e 24/04/2009, com espaçamento de $0,16 \mathrm{~m}$ entre linhas, na profundidade de aproximadamente 3 centímetros e densidade de semeadura de 70 sementes por metro. As parcelas foram constituídas por 15 linhas de 6 metros de comprimento. Para as avaliações, utilizou-se área útil de $3,2 \mathrm{~m}^{2}$, em que foram consideradas apenas as cinco fileiras centrais.

O delineamento experimental utilizado foi em blocos casualizados com quatro repetições, em esquema fatorial $2 \times 5$ (dois estádios e cinco doses). Os tratamentos quantitativos constituíram-se nas cinco doses do herbicida metsulfuron-methyl: $0 ; 1,8 ; 3,6$; 5,$4 ; 7,2$ g i.a. ha $^{-1}$, o que corresponde a $0 ; 3 ; 6$; 9; $12 \mathrm{~g} \mathrm{ha}^{-1}$, respectivamente, do produto comercial Ally ${ }^{\circledR}$.

As aplicações foliares foram efetuadas nos estádios de desenvolvimento 4 (após perfilhamento intenso) e 10.4 (75\% das espigas visíveis).
Para as aplicações foliares, utilizou-se pulverizador costal pressurizado à $\mathrm{CO}_{2}$, com pressão constante de 2 BAR (ou 29 PSI), vazão de $0,65 \mathrm{~L} \mathrm{~min}^{-1}$, equipado com lança contendo uma ponta tipo leque da série Teejet modelo XR 110.02, que, trabalhando a uma altura de $50 \mathrm{~cm}$ do alvo, com velocidade de $1 \mathrm{~m}$ segundo $^{-1}$, atingindo faixa aplicada de $50 \mathrm{~cm}$ de largura, propiciou volume de calda de $200 \mathrm{~L}$ $\mathrm{ha}^{-1}$.

Durante o desenvolvimento da cultura do trigo, após a aplicação do herbicida (em dias após aplicação - DAA, ou próximo a colheita), foram realizadas avaliações visuais de algumas características, como níveis de coloração e fitotoxicidade (3 e 7 DAA), altura de plantas, acamamento e germinação na espiga (précolheita).

Partindo-se do rendimento de sementes nas parcelas, foram calculadas as produtividades em $\mathrm{kg} \mathrm{ha}{ }^{-1}$, para cada tratamento. Em seguida, foi determinada a massa de mil sementes, por meio da pesagem de oito subamostras de 100 sementes, para cada repetição, com o auxílio de balança analítica com precisão de um miligrama, multiplicandose os resultados por 10. Para o cálculo do rendimento e da massa de mil sementes, o grau de umidade foi determinado por meio do método de estufa a $105^{\circ} \mathrm{C}$ (Brasil, 1992), com correção para $13 \%$ de umidade.

A qualidade fisiológica das sementes foi avaliada por meio dos testes de germinação (indicativo de viabilidade) e primeira contagem do teste de germinação (indicativo de vigor).

$\mathrm{O}$ teste de germinação foi realizado com quatro subamostras de 100 sementes para cada tratamento e repetição de campo. As sementes foram semeadas entre três folhas de papeltoalha (germiteste) umedecidas com água destilada, utilizando-se a quantidade de água equivalente a três vezes a massa do papel seco. Foram confeccionados rolos sendo estes levados para germinador do tipo Mangelsdorf, 
regulado para manter constante a temperatura de $20^{\circ} \mathrm{C}$, por um período de oito dias. Os resultados foram expressos em porcentagem de plântulas normais, segundo as prescrições contidas nas Regras para Análise de Sementes (Brasil, 1992). A primeira contagem do teste de germinação: foi efetuada em conjunto com o teste de germinação, computando-se a porcentagem de plântulas normais obtidas no quarto dia após a semeadura (Brasil, 1992).

Os dados foram submetidos à análise de variância, sendo o teste $F$ conclusivo para estádios e aplicada análise de regressão para os tratamentos quantitativos (doses), em diferentes níveis de probabilidade (até 15\%), efetuando-se os desdobramentos necessários. Não foi necessária a transformação dos dados. Para a escolha do melhor modelo de regressão foram adotados os seguintes critérios: regressão significativa, desvios da regressão não-significativos, coeficiente de determinação e análise de resíduos.

\section{Resultados e discussão}

Durante o desenvolvimento da cultura foram realizadas avaliações visuais de suas características, como níveis de coloração, redução de tamanho e fitotoxicidade, mas não foram observadas alterações visuais representativas ou efeitos fitotóxicos consideráveis, bem como qualquer outro dano que pudesse causar efeitos deletérios significativos à cultura. Tal descrição de fatos não corrobora com o afirmado por Salvagiotti et al. (2001) e corrobora parcialmente com Papa et al. (2005), no tocante à constatação de fitotoxicidade sobre a cultura.

Os resultados explanados por Papa et al. (2005) apontam a existência de sintomas visuais de fitotoxicidade em ensaio no ano de
2001, em que 15 dias após a aplicação identificou-se uma leve clorose, visualizada nos tratamentos que receberam 6 e 9 g i.a. ha ${ }^{-1}$ de metsulfuron-methyl, notando que 30 dias após, estes sintomas não foram mais percebidos.

Em experimento na safra 2002, Papa et al. (2005) realizaram avaliações, em que não foi revelado sintomas visuais de fitotoxicidade, mesmo nas doses mais elevadas, o que foi justificado devido às excelentes condições ambientais que ocorreram durante a execução deste experimento, o que permitiu um rápido metabolismo do herbicida.

Os resultados obtidos, concernentes aos componentes de produção, nas duas safras experimentais estão apresentados nas Tabelas 1, 2 e 3, além da Figura 1.

O conjunto de dados apenas permitiu desdobramento para a interação entre "Estádio" x " Dose" para a safra 2008, em que as doses aplicadas no período vegetativo (considera-se aqui: após perfilhamento intenso - estádio de desenvolvimento 4) tenderam a apresentar valores superiores para a variável produtividade $(P<0,13)$, quando comparadas ao reprodutivo (assume-se aqui: $75 \%$ das espigas visíveis - estádio de desenvolvimento 10.4).

Foi possível ajustar um modelo de regressão polinomial significativo para doses $(P<0,10)$, especificamente dentro do estádio reprodutivo, no qual se verificou decréscimo linear da produtividade em função do aumento nas doses do metsulfuron-methyl. Para o aumento de cada $\mathrm{g} \mathrm{ha}^{-1}$ do produto Ally ${ }^{\circledR}$ (a base de metsulfuron-methyl), diminuíram $30,69 \mathrm{~kg} \mathrm{ha}^{-1}$ da produtividade de sementes de trigo, na safra 2008. 
Tabela 1. Produtividade $\left(\mathrm{kg} \mathrm{ha}^{-1}\right)$ e massa de 100 sementes $(\mathrm{g})$, em resposta às diferentes doses do herbicida metsulfuron-methyl, aplicadas em dois estádios, na safra de 2008.

\begin{tabular}{|c|c|c|}
\hline $\begin{array}{l}\text { Doses de } \text { Ally }^{(\circledR)} \text { - metsulfuron-methyl } \\
\qquad\left(\mathrm{g} \mathrm{ha}^{-1}-\mathrm{g} \text { i.a. } \mathrm{ha}^{-1}\right)\end{array}$ & $\begin{array}{l}\text { Produtividade } \\
\qquad\left(\mathrm{kg} \mathrm{ha}^{-1}\right)\end{array}$ & 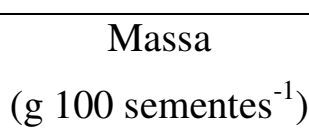 \\
\hline $0-0$ & 2264,96 & 4,43 \\
\hline $3-1,8$ & 2151,97 & 4,43 \\
\hline $6-3,6$ & 2014,85 & 4,46 \\
\hline $9-5,4$ & 2046,93 & 4,42 \\
\hline $12-7,2$ & 1977,03 & 4,45 \\
\hline Estádio Vegetativo & 2035,45 & 4,43 \\
\hline Estádio Reprodutivo & 2146,84 & 4,45 \\
\hline Média geral & 2091,15 & 4,44 \\
\hline $\mathrm{CV}(\%)$ & 10,89 & 2,81 \\
\hline$P$ Dose & 0,10 & 0,97 \\
\hline$P$ Estádios & 0,13 & 0,75 \\
\hline
\end{tabular}

Na segunda safra (2009), para a variável reprodutivo diminuíram a produtividade produtividade, caracterizou-se diferença significativa apenas para o fator "estádios" as aplicações no vegetativo. Não houve efeito (efeito principal), em que aplicações no estádio significativo dentro dos desdobramentos.

Tabela 2. Produtividade $\left(\mathrm{kg} \mathrm{ha}^{-1}\right)$ e Massa de 100 sementes $(\mathrm{g})$, em resposta as diferentes doses do herbicida metsulfuron-methyl, aplicadas em dois estádios, na safra de 2009.

\begin{tabular}{|c|c|c|}
\hline $\begin{array}{c}\text { Doses de Ally }{ }^{\circledR} \text { - metsulfuron-methyl } \\
\left(\mathrm{g} \mathrm{ha}^{-1}-\mathrm{g} \text { i.a. } \mathrm{ha}^{-1}\right)\end{array}$ & $\begin{array}{l}\text { Produtividade } \\
\left(\mathrm{kg} \mathrm{ha}^{-1}\right)\end{array}$ & 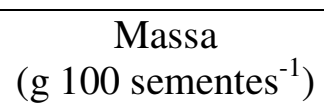 \\
\hline $0-0$ & 1376,22 & 4,06 \\
\hline $3-1,8$ & 1408,27 & 3,96 \\
\hline $6-3,6$ & 1371,90 & 4,08 \\
\hline $9-5,4$ & 1325,81 & 4,03 \\
\hline $12-7,2$ & 1363,48 & 3,93 \\
\hline Estádio Vegetativo & 1416,12 & 4,02 \\
\hline Estádio Reprodutivo & 1322,16 & 4,00 \\
\hline Média geral & 1369,14 & 4,01 \\
\hline $\mathrm{CV}(\%)$ & 7,19 & 2,57 \\
\hline$P$ Dose & 0,585 & 0,037 \\
\hline$P$ Estádios & 0,006 & 0,420 \\
\hline
\end{tabular}

Quanto à variável massa de sementes, não identificado efeito significativo para o fator foi possível detectar efeitos significativos para "doses" $(P<0,04)$, no entanto, não foi possível a safra 2008, seja nos efeitos principais ou o ajuste de um modelo de regressão adequado, interação $(P<0,15)$. Porém, na safra 2009 foi segundo critérios adotados para seleção 
(regressão significativa, desvios da regressão não-significativos, coeficiente de determinação e análise de resíduos).

Tabela 3. Produtividade $\left(\mathrm{kg} \mathrm{ha}^{-1}\right)$ no estádio vegetativo (após perfilhamento intenso) e reprodutivo (75\% das espigas visíveis) da cultura do trigo, em resposta as diferentes doses do herbicida metsulfuron-methyl, aplicadas em dois estádios, na safra de 2009.

\begin{tabular}{ccc}
\hline Dose & $\begin{array}{c}\text { Produtividade } \\
\text { Vegetativo } \\
\left(\mathrm{kg} \mathrm{ha}^{-1}\right)\end{array}$ & $\begin{array}{c}\text { Produtividade } \\
\text { Reprodutivo } \\
\left(\mathrm{kg} \mathrm{ha}^{-1}\right)\end{array}$ \\
\hline $0-0$ & 1423,17 & 1329,27 \\
$3-1,8$ & 1418,37 & 1398,17 \\
$6-3,6$ & 1411,33 & 1329,47 \\
$9-5,4$ & 1362,55 & 1289,06 \\
$12-7,2$ & 1462,15 & 1264,82 \\
\hline Média * & $1416,12 \mathrm{~A}$ & $1322,16 \mathrm{~B}$
\end{tabular}

*Letras diferentes na mesma linha, indicam que os resultados diferem entre si a 5\% pelo teste $\mathrm{F}$.

Portanto, analisando-se as variáveis referentes aos componentes de produção, presentes no experimento, e assumindo que altas doses de metsulfuron-methyl podem ser utilizadas em diferentes estádios de desenvolvimento pelos agricultores e, supondo que o emprego dessas doses em combinação com o estádio de desenvolvimento possa afetar a planta; a partir dos resultados obtidos foi possível constatar que, o herbicida metsulfuron-methyl, aplicado em altas doses no período reprodutivo, tende a diminuir a produtividade (Figura 1 e Tabela 3 ).

Porém, aplicações no estádio vegetativo não apresentam efeitos significativos até $15 \%$ de probabilidade, nos dois anos, tanto para produtividade como para massa de cem sementes, notando que esta última variável também não se manifestou de maneira significativa no estádio reprodutivo.
A inexistência de efeitos relevantes em algumas variáveis sob determinadas condições nestes ensaios, pode ser atribuída à situações ambientais reinantes e influentes na cultura, nestes dois anos agrícolas, menciona-se, por exemplo, que o clima predominante no período não favoreceu a produtividade em ambas as safras (as produtividades estiveram inferiores a $2265 \mathrm{~kg} \mathrm{ha}^{-1}$ ). Deve-se salientar que em outras condições edafoclimáticas podem ou não haver danos de maior intensidade à cultura (Leaden, 2002), no entanto, é importante ressaltar que os resultados apresentados corroboram parcialmente com os de Papa et al. (2005) e Salvagiotti et al. (2001).

No trabalho de Papa et al. (2005), os autores observaram que apesar do uso de doses não recomendadas para uso prático - altas doses (como verificado no presente trabalho), para as condições em que se realizaram os experimentos, concluíram que os diferentes tratamentos com metsulfuron-methyl não afetaram significativamente a biomassa e a produtividade da cultura do trigo.

A partir dos resultados obtidos, pode-se inferir que o herbicida a base de metsulfuronmethyl, quando aplicado em altas doses no período reprodutivo, tende a diminuir a produtividade da cultura; porém aplicações no vegetativo não apresentam efeitos negativos significativos.

Avaliando-se a qualidade das sementes de trigo sob o efeito da aplicação de doses crescentes de metsulfuron-methyl em diferentes estádios de desenvolvimento e a interação entre os mesmos, e assumindo que altas doses deste produto podem afetar o desenvolvimento da planta e consequentemente expressar efeitos deletérios na qualidade fisiológica das sementes, foram obtidos os resultados representados nas Tabelas 4 e 5 . 


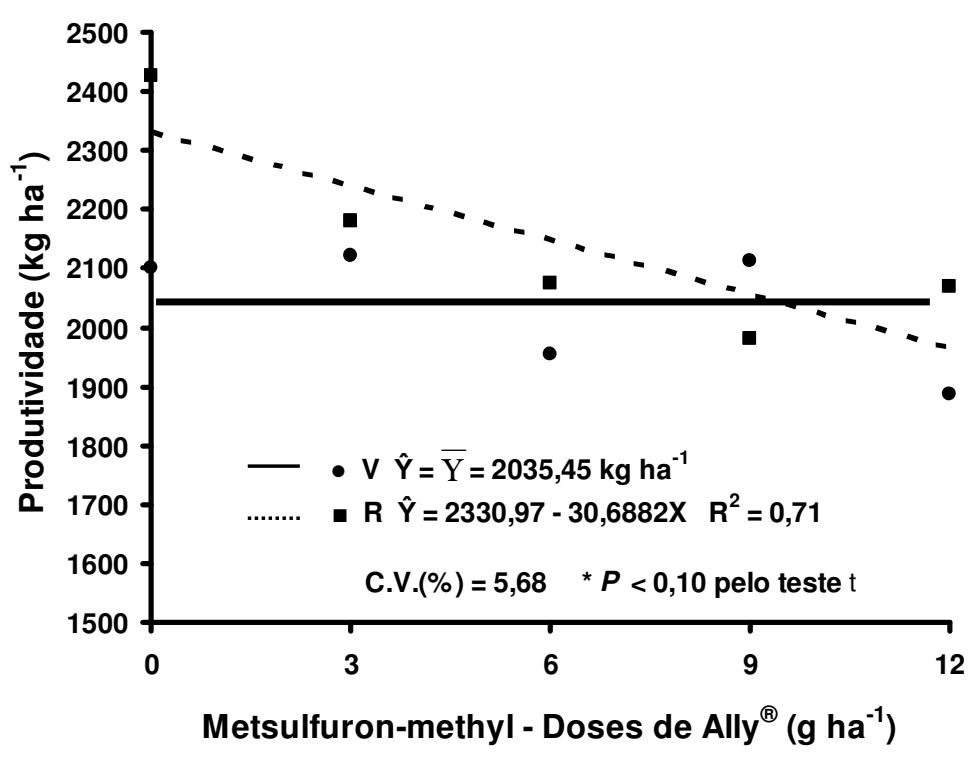

Figura 1: Regressão polinomial da produtividade de trigo $\left(\mathrm{kg} \mathrm{ha}^{-1}\right)$, em função da aplicação de doses do herbicida metsulfuron-methyl ( $\mathrm{g} \mathrm{ha}^{-1}$ do produto $\left.\mathrm{Ally}^{\circledR}\right)$, em dois estádios da cultura: vegetativo - 4 (após perfilhamento intenso) e reprodutivo - 10.4 (75\% das espigas visíveis), na safra de 2008.

No ano agrícola de 2008, observou-se aplicações no estádio vegetativo, estas não diminuição do vigor $(P<0,03)$, quando o apresentam efeitos significativos até $15 \%$ de herbicida foi aplicado no estádio reprodutivo probabilidade na safra de 2008 e 2009 . Em se em altas doses, fato este que não se repetiu no tratando de germinação, esta variável não ano de 2009, possivelmente relacionado às sofreu diferenças significativas, em ambos os condições ambientais predominantes na estádios e doses de aplicação, nas duas safras localidade e influentes no cultivo. Quanto à agrícolas.

Tabela 4. Porcentagem de vigor e germinação das sementes de trigo, em resposta as diferentes doses do herbicida metsulfuron-methyl, aplicadas em dois estádios, na safra de 2008.

\begin{tabular}{ccc}
\hline $\begin{array}{c}\left.\text { Doses de Ally }{ }^{(}\right) \\
\left(\mathrm{g} \mathrm{ha}^{-1}-\mathrm{g} \text { i.a. ha }\right)\end{array}$ & $\begin{array}{c}\text { Vigor } \\
(\%)\end{array}$ & $\begin{array}{c}\text { Germinação } \\
(\%)\end{array}$ \\
\hline $0-0$ & 95,19 & 99,16 \\
$3-1,8$ & 94,31 & 99,19 \\
$6-3,6$ & 93,97 & 99,22 \\
$9-5,4$ & 94,63 & 99,28 \\
$12-7,2$ & 94,38 & 99,19 \\
\hline Estádio Vegetativo & 94,98 & 99,28 \\
\hline Estádio Reprodutivo & 94,01 & 99,14 \\
\hline Média geral & 94,49 & 99,21 \\
\hline CV $(\%)$ & 1,24 & 0,71 \\
\hline$P$ Dose & 0,33 & 0,99 \\
\hline$P$ Estádios & 0,02 & 0,54 \\
\hline
\end{tabular}


A partir dos resultados obtidos, pode-se dizer que $\mathrm{o}$ herbicida metsulfuron-methyl mesmo aplicado em altas doses, nos estádios vegetativo e reprodutivo, não causou danos severos na qualidade fisiológica das sementes de trigo, nos anos agrícolas de 2008 e 2009 . No entanto, é possível que aplicações no reprodutivo possam diminuir o vigor das sementes em determinadas safras, em determinadas cultivares e sob certas condições ambientais. Para melhor elucidar a relação entre as diferentes variáveis relacionadas ao sistema produtivo, é necessária a ampliação das pesquisas, sobretudo as que abrangem na busca de relacionar a questão da qualidade de sementes.

Tabela 5. Porcentagem de vigor e germinação das sementes de trigo, em resposta as diferentes doses do herbicida metsulfuron-methyl, aplicadas em dois estádios, na safra de 2009.

\begin{tabular}{ccc}
\hline $\begin{array}{c}\text { Doses de Ally }{ }^{\circledR}-\text { metsulfuron-methyl } \\
\left(\mathrm{g} \mathrm{ha}^{-1}-\mathrm{g} \text { i.a. ha }\right)\end{array}$ & $\begin{array}{c}\text { Vigor } \\
(\%)\end{array}$ & $\begin{array}{c}\text { Germinação } \\
(\%)\end{array}$ \\
\hline $0-0$ & 85,25 & 91,13 \\
$3-1,8$ & 86,69 & 91,13 \\
$6-3,6$ & 84,94 & 89,19 \\
$9-5,4$ & 84,31 & 88,88 \\
$12-7,2$ & 84,75 & 90,13 \\
\hline Estádio Vegetativo & 85,08 & 89,85 \\
\hline Estádio Reprodutivo & 85,30 & 90,33 \\
\hline Média geral & 85,19 & 90,09 \\
\hline CV $(\%)$ & 3,31 & 3,09 \\
\hline$P$ Dose & 0,521 & 0,358 \\
\hline$P$ Estádios & 0,803 & 0,594
\end{tabular}

\section{Conclusão}

A partir dos resultados obtidos, pode-se inferir que o herbicida utilizado, a base de metsulfuron-methyl, pode ser prejudicial à cultura do trigo, cultivar IPR 85, apenas quando o incremento das doses ocorre durante aplicações no estádio de espigamento.

\section{Referências}

BRASIL. Ministério da Agricultura e Reforma Agrária. Regras para análise de sementes. Brasília: SNDA/DNDV/CLAV, 1992. 365p.

COMISSÃO SUL-BRASILEIRA DE PESQUISA DE TRIGO, 37, 2005, Passo Fundo. Indicações técnicas da comissão sulbrasileira de pesquisa de trigo e triticale -
2005 e 2006. Passo Fundo: Embrapa Trigo, 2005. 119 p.

EMBRAPA. Sistema brasileiro de classificação dos solos. Embrapa: Brasília, 1999. 412p.

IAPAR. Cartas climáticas básicas do Estado do Paraná. Londrina: Instituto Agronômico do Paraná, 1987. 35p.

IQBAL, J.; WRIGHT, D. Effects of weed competition on flag leaf photosynthesis and grain yield of spring wheat. Weed Research, v.32, n.1, p.23-30, 1999.

LEADEN, M.I. Herbicidas para malezas de hoja ancha en trigo. INTA: Balcarce. p. 4548. 2002.

PAPA C. J. et al. Efecto del herbicida metsulfurón metil sobre el rendimiento de un 
cultivo de trigo pan. Revista Para Mejorar la

Producción. v.28, n.1, p.56-58, 2005.

SALVAGIOTTI, F. et al. Efecto de la sobredosis de metsulfurón metil sobre el cultivo de trigo con diferentes niveles de fertilidad. Revista Para Mejorar la

Producción. v.16, n.3, p.53-55, 2001.

VARGAS, L; ROMAN, E.S. Seletividade e eficiência de herbicidas em cereais de inverno.

Revista Brasileira de Herbicidas, v.4, n.3, p.

1-10, 2005. 